\title{
Body composition and peak aerobic power in male international level Hungarian athletes
}

\author{
R. Frenkl, J. Mészáros, Y. A. Soliman, J. Mohácsi \\ Faculty of Physical Education and Sport Sciences, Semmelweis University, Budapest, Hungary
}

Received: February 11, 2002

Accepted: March 12, 2002

\begin{abstract}
Body size, physique, body composition and physiological performance of elite athletes are independent aspects, have aroused the interest of exercise scientists, but studies that combine these aspects in elite athletes are scarcely available.

The aim of the present study was to describe the selected anthropometric and exercise physiological characteristics of some Hungarian top athletes.

The investigated subjects were qualified Hungarian water polo players $(n=25)$, paddlers $(n=24)$ and modern pentathlonists $(n=20)$, all of whom had been medalists at several continental and intercontinental competitions. The athletes' body composition was estimated by the Drinkwater-Ross (45) body mass fractionation technique. Peak physiological performance was estimated by graded exhausting spiroergometric treadmill exercise.

Intergroup differences in mean height, body mass and body composition characteristics were significant at the $5 \%$ level of random error. By the results of spiroergometry, all the three groups compared could be qualified as physically excellently trained. The greatest oxygen uptake relative to body mass was found in the modern pentathlonists $\left(73.22 \mathrm{ml} \times \mathrm{kg}^{-1} \times \mathrm{min}^{-1}\right)$ and the lowest one (59.79) in the water polo players. The authors do not disregard the favourable effects of regular and adequate trainings in the development of the studied characteristics, but in their opinion the process of proper selection has been the most important factor that explains the observed significant intergroup differences.
\end{abstract}

Keywords: qualified male athletes, relative bone-, muscle- and fat mass, relative aerobic power

Body dimensions, physique, body composition and physiological performance of elite athletes have always been topics of interest for exercise scientists. Relatively low body fat, larger muscle mass, muscularity and excellent aerobic power are desirable features when it comes to optimise athletic performance in many kinds of sports $(2,9$,

Correspondence should be addressed to

Robert Frenkl

Faculty of Physical Education and Sport Sciences

Semmelweis University

H-1123 Budapest, Alkotás u. 44, Hungary 
12, 13, 22). As single properties these are relatively frequent even in the general population, but to find individuals with several of these necessary qualities is a very difficult task (10). Separately, neither anthropometric nor exercise physiological investigations of athletes are not rare in the scientific literature, also some anthropometric reference data have been published (3,21, 23), however, studies to date that combine these aspects have been unavailable.

The aim of the present study was to describe the most important anthropometric and exercise physiological characteristics of some Hungarian top athletes. We have supposed that the human biological properties of these elite athletes represent extreme values in respect of the population, and these are attributable to the process of continuous selection firstly, and to their vigorous physical training secondly.

\section{Subjects and Methods}

The subjects were volunteer Hungarian athletes all of whom were of international rank during the past three Olympic cycles.

WATER POLO players $(n=25)$ : they represent $30 \%$ of the Hungarian League I and $95 \%$ of the National Water Polo Team for the past 2 years. They won the bronze medal at the past World Cup, the gold one at the European Championship (1997), silver medal at the World Championship in 1998, and they won Olimpic gold in Sydney (2000).

PADDLERS ( $n=24)$ : they represent $42 \%$ of the Hungarian League I and all the 24 athletes were member of the Hungarian National Team in the past 3 years. They won 25 golds at the World Championships, 31 medals at the European Championships and 4 gold, 6 silver and 10 bronze medals at the Atlanta and Sydney Olympic Games.

MODERN PENTATHLONISTS ( $n=20)$ : they represent $40 \%$ of the Hungarian League I and $100 \%$ of the national teams of the past 6 years. The sample consists of European and World champions as well as medalists and Olympic medalists.

These three events have belonged to the most successful ones in Hungary, nevertheless, these sports are not the most popular ones among the youngsters. In addition to the very strict selection criteria (all the athletes have won medals) this lack of popularity may explain the moderate sample sizes.

The athletes' body composition was estimated by the Drinkwater-Ross (5) body mass fractionation technique. In taking the necessary body dimensions the IBP suggestions (25) were observed. For the graded exhausting spiroergometric test run a $\mu$ DATASPIR model gas analyser and a treadmill (Jaeger, Germany) were used. Following individual warm-up the test exercise began at zero level incline and $12 \mathrm{kmh}$. Work rate was increased every second minute by increasing the belt inclination by $3 \%$. 
Differences between the subgroup means and standard deviations were tested by oneway ANOVA. When the F-test was significant, Scheffé's critical differences were also calculated.

\section{Results}

Descriptive and comparative statistics for the investigated anthropometric variables are shown in Table I. If the difference between the respective means was significant at the $5 \%$ level of random error, the critical difference is shown in the last column of Table I.

Chronological age of the water polo team was significantly younger than that the paddlers or modern pentathlonists. The mean height of water polo players was the tallest while the average difference between the stature of paddlers and modern pentathlonists was not significant. The water polo players were also the heaviest, however, the difference between the mean body mass of paddlers and modern pentathlonist was also significant. The paddlers were heavier. The heights and body masses of the three compared groups were essentially larger than the Hungarian reference values (16).

\section{Table I}

Body composition of qualified athletes

\begin{tabular}{|c|c|c|c|c|c|c|c|}
\hline \multirow[b]{2}{*}{ Var. } & \multicolumn{2}{|c|}{ Water polo } & \multicolumn{2}{|c|}{ Paddling } & \multicolumn{2}{|c|}{ Modern pentath. } & \multirow[b]{2}{*}{$\mathrm{CD}$} \\
\hline & Mean & $\mathrm{SD}$ & Mean & $\mathrm{SD}$ & Mean & SD & \\
\hline $\mathrm{CA}$ & 24.08 & 3.32 & 25.77 & 2.18 & 27.18 & 2.61 & 2.16 \\
\hline $\mathrm{BH}$ & 190.92 & 5.95 & 185.03 & 4.47 & 182.96 & 5.38 & 3.43 \\
\hline BW & 91.08 & 7.69 & 80.64 & 4.87 & 73.18 & 5.62 & 4.93 \\
\hline $\mathrm{B} \%$ & 16.23 & 0.70 & 17.26 & 0.41 & 16.69 & 0.89 & 0.44 \\
\hline M\% & 46.90 & 1.27 & 49.08 & 0.85 & 48.43 & 1.29 & 0.74 \\
\hline $\mathrm{F} \%$ & 10.78 & 1.74 & 7.73 & 0.95 & 8.34 & 1.11 & 1.05 \\
\hline
\end{tabular}

Abbreviations:

$\mathrm{CA}$ : calendar age (yr.)

BH: height $(\mathrm{cm}) ; \mathrm{BW}=$ body weight $(\mathrm{kg})$

$\mathrm{B} \%$ : bone mass relative to body weight; $\mathrm{M} \%=$ muscle mass relative to body weight

F: fat mass relative to body weight

$\mathrm{CD}$ : critical difference calculated by Scheffé

$\mathrm{F}_{5 \%, 2,66}=2.73$ 
Table II

Peak-exercise physiological characteristics of qualified athletes

\begin{tabular}{|c|c|c|c|c|c|c|c|}
\hline \multirow[b]{2}{*}{ Var. } & \multicolumn{2}{|c|}{ Water polo } & \multicolumn{2}{|c|}{ Paddling } & \multicolumn{2}{|c|}{ Modern pentath. } & \multirow[b]{2}{*}{$\mathrm{CD}$} \\
\hline & Mean & SD & Mean & SD & Mean & SD & \\
\hline HR & 185.05 & 5.47 & 187.92 & 4.72 & 184.65 & 3.97 & NS \\
\hline $\mathrm{RVO}_{2}$ & 59.79 & 4.98 & 69.23 & 3.94 & 73.22 & 4.52 & 3.44 \\
\hline $\mathrm{O}_{2} \mathrm{P}^{2}$ & 29.15 & 2.54 & 29.69 & 1.99 & 29.15 & 2.34 & NS \\
\hline MV & 154.16 & 17.70 & 162.96 & 14.78 & 150.73 & 19.38 & 10.86 \\
\hline RMV & 1.69 & 0.19 & 2.02 & 0.18 & 2.06 & 0.26 & 0.13 \\
\hline
\end{tabular}

Abbreviations:

HR: heart rate (bpm)

$\mathrm{RVO}_{2}$ : oxygen uptake relative to body weight $\left(\mathrm{ml} \times \mathrm{kg}^{-1} \times \mathrm{min}^{-1}\right)$

$\mathrm{O}_{2} \mathrm{P}$ : oxygen pulse $\left(\mathrm{ml} \times\right.$ beat $\left.^{-1}\right) ; \mathrm{MV}=$ minute ventilation $\left(1 \times \mathrm{min}^{-1}\right)$

RMV: minute ventilation relative to body weight $\left(1 \times \mathrm{kg}^{-1} \times \mathrm{min}^{-1}\right)$

CD: critical difference calculated by Scheffé

NS: differences between the means are not significant

Relative bone mass differed significantly in these samples. Water polo players can be characterized by the lowest bone percentage relative to body mass, and the paddlers have the most robust skeletal system. The most developed skeleton was associated with the highest muscle percentage (49.08\%), and the lowest relative bone was found with the smallest relative muscle mass $(46.90 \%)$. The muscle mass means relative to body weight were similar in the paddlers and modern pentathlonists. As characteristic of the elite athletes, relative fat mass was low, in all the three groups compared. Nevertheless, the water polo players had the largest amount of body fat $(10.78 \%)$, and the paddlers were the leanest $(7.78 \%)$. The mean difference of relative body fat content between the paddlers and modern pentathlonists was not significant at the $5 \%$ level of random error.

The peak exercise physiological parameters are shown in Table II. The arrangement of this table agrees with Table I. The heart rate means (ranging between $185-188 \mathrm{bpm})$ and the oxygen pulse means (29-30 ml $\times$ beat $\left.^{-1}\right)$ were statistically similar, indicating the intensity of test exercise and also the excellent condition of the investigated athletes. All the three groups were homogenous in respect of the mentioned variables.

Mean oxygen uptake relative to body mass was the largest in the modern pentathlonists and the smallest in the water polo players. The differences were significant in all the possible comparisons.

The means of minute ventilation were close to each other. The only significant difference could be observed between the paddlers and modern pentathlonists. Minute ventilation in well-trained athletes correlates with body dimensions in general, but the 
difference observed could not be explained by the differences in height and body mass alone. Excluding the significant differences between the observed body masses, the smallest volume of relative minute ventilation (minute ventilation: body mass) was found in the water polo players while this calculated parameter did not differ between the groups of paddlers and modern pentathlonists.

\section{Discussions}

The significant intergroup differences shown are characteristic above all, of the given sports, and the similarities have arisen from the athletes' excellence of sport performance, in our opinion. The last statement is not merely a theoretical conclusion. The investigated athletes have proven their talent and competence consistently during the championships.

The marked differences are attributable to the essentially different physical and physiological requirements of the compared activities. The only exception is the calendar age in this respect. The younger calendar age of the water polo players can be explained by the fact that following some less successful continental competitions a new National Team was created by a new head coach. The new coach was given the advantage of including the younger generation, first of all those players who had won Junior World Championships 4 years ago.

In our opinion, the calendar age differences of 1.5-3.0 years have no significant effects on body composition and physiological performance capacity over the age of 20 .

A taller height and more or less heavier body mass are favourable in many kinds of sports, if the athletes' other physical and physiological abilities are at a similar level. The observed means of height and body mass that were markedly larger than the Hungarian population averages (by one or two SD's; Joubert and Gyenis 2001) have been attributed to sport selection effects.

The three compared groups had significantly different body composition. A less than $11 \%$ fat content is characteristic of elite athletes and is a favourable feature even when one takes account of the possible differences between the various procedures of estimation $(6,20,19)$. According to Wilmore (26), and Heyward and Stolarczyk (7) relative body fat content is significantly greater in water sport competitors than in land competitors. Thermoregulation is a serious problem in water sports. Not especially in the competitions, but above all during the significantly longer trainings. The insulation effect of subcutaneous fat is just one side of the problem in our opinion. For instance, smaller body density due to the larger body fat content is an advantage in water sports. In most other sports, however, a higher than necessary fat percentage may affect physiological performance adversely. In this respect, two of our results, namely the 
significantly smaller bone and muscle ratios of the water polo players, are likely to be of importance. Both of them influence body density. Concerning relative muscle and bone masses, our work group using the same technique have published data for adult and young athletes $(14,15,17,18)$. A bone percentage of between 16-17 can be qualified as an above average one in nonathletes.

In our opinion, the characteristic differences between the relative bone mass means were independent of training effects and belong to the consequences of spontaneous selection in sports. Players with a heavy skeletal system (and having consequently greater body density) would generally not be successful in water polo. The rank order in relative bone mass was: paddlers, modern pentathlonists (modern pentathlon also contains $300 \mathrm{~m}$ swimming) and water polo players.

In contrast with fat content, the differences in relative muscle mass could be easily related to training effects, especially to the physical requirements of the compared sports.

In respect of the peak-exercise physiological variables it may be stated, the investigated athletes represented very highly qualified samples. Their relative mean oxygen uptake exceeded all the comparable results $(9,20,22,24)$, though an extremely high aerobic power is not the only determinant of athletic performance and success. Beyond the observed very favourable exercise physiological means, we have to stress also the moderate variability around the respective means in all the three groups. The only exception was pulmonary ventilation in this respect.

Physiological working capacity is one of the main determinants of elite sport performance. Though training adaptation in the compared physiological functions has never been questioned, to reach an oxygen pulse of more than $29 \mathrm{ml} \times \mathrm{beat}^{-1}$ and pulmonary ventilation volume more than $1501 \times \mathrm{min}^{-1}$ is impossible without adequate training. Demeter (4) has stressed that relative ventilation volumes of $2 \mathrm{l} \times \mathrm{kg}^{-1} \times \mathrm{min}^{-1}$ indicates excellent respiratory functions even in children and especially in adults. However, one cannot exclude sport selection effects and heredity completely even in this respect. Malina and Bouchard (11) and also Bouchard and associates (1) have described the importance of heredity in the level of aerobic performance and also in the training induced development of peak aerobic power. Thus, one has to find, the suitable youngsters firstly.

The conclusions are as follows. The investigated elite athletes represent a highly selected sample both in an anthropometric and exercise physiological sense. We do not question the favourable effects of regular and adequate training, but we stress that not every healthy child and youngster is suitable for top athletics, even in spite of the best available training. The dominant part of the elite athletes' attributes that determine sport performance belongs to the inherited characters (e.g. tall stature, athletic physique, high aerobic and anaerobic power, the rate of the training-induced development, etc.). 
In this way, selection, education and training have similar relative weights in the preparation process, but one must be aware of the fact proper and reliable selection is the hardest part of this procedure.

Since inadequacies in any of the studied characteristics cannot be compensated for by improving another at this level of sports performance, we think it is indispensable to study at least this or a more comparable set of biological variables for a correct and reliable assessment of the athletes' physiological performance.

\section{REFERENCES}

1. Bouchard C, Dionne FT, Simonneau JA, Boulay MR: Genetics of aerobic and anaerobic performance. Exercise and Sport Science Reviews 20, 27-58 (1992)

2. Carter JEL, Aubry SP, Sleet DA (1982): Somatotypes of Montreal Olympic athletes. In Carter JEL (Ed.): Physical Structure of Olympic Athletes. Karger, New York, pp. 53-80

3. Carter JEL, Heath BH (1990): Somatotyping Development and Applications. Cambridge University Press, Cambridge-New York-Port Chester-Melbourne-Sydney

4. Demeter A (1981): Sport im Wachstums- und Entwicklungsalter. Anatomische, physiologische und psychologische Aspekte. Johann Ambrosius Barth, Leipzig.

5. Drinkwater DT, Ross W (1980): Anthropometric fractionation of body mass. In Ostyn M, Beunen G, Simons J (Eds): Kinanthropometry II. University Park Press, Baltimore, pp. 178-189

6. Fleck SJ: Body composition of elite American athletes. Am. J. of Sports Med. 11, 398-403 (1983)

7. Heyward, VH, Stolarczyk LM (1996): Applied Body Composition Assessment. Human Kinetics, Champaign, Illionois. pp 147-154

8. Joubert K, Gyenis Gy: A 18 éves sorköteles ifjak egészségi állapota, testfejlettsége, I. KSH NKI Kutatási Jelentések 70, Budapest, 131 (2001)

9. Konopka P: Ausdauer und Ausdauertraining. Deutsche Zeitschrift für Sportmedizin 3, 76-82 (1981)

10. Kovár R (1981): Human Variations in Motor Abilities and its Genetic Analysis. Charles University, Prague

11. Malina RM, Bouchard C (1991): Growth, Maturation and Physical Activity. Human Kinetics, Champaign, Illinois.

12. Mercier J, Varray A, Ramonatxo-Mercier B, Préfaut C: Influence of anthropometric characteristics on changes of maximal exercise ventilation and breathing pattern during growth in boys. European J. of Appl. Physiol. 63, 235-241 (1991)

13. Mészáros J, Mohácsi J: An anthropometric study of top level athletes in view of the changes that took place in style of some ball games. Humanbiologia Budapestinensis 13, 15-21 (1982)

14. Mészáros J, Frenkl R, Petrekanits M, Farkas A, Mohácsi J (1992): Anthropometric and exercise physiological characteristics of young male athletes grouped by weight-related aerobic power. In Coudert J, Van Praagh E (Eds): Children and Exercise XVI Pediatric Work Physiology. Masson, Paris, Milan, Barcelona, Bonn, pp. 147-150

15. Mészáros T, Szabó A, Prókai J, Mohácsi J, Frenkl R (1997): A young to adult comparison of exercise plasma volume decrease. In Armstrong N, Kirby BJ, Welsman JR (Eds): Children and exercise XIX. E and FN SPON, London, Weinheim, New York, Tokyo, Melbourne, Madras, pp. 405-411

16. Mohácsi J, Mészáros J: Stature and body mass in Hungarian schoolchildren between 7 and 18. 13th School of Biological Anthropology, Zagreb, 23-25 (1987)

17. Mohácsi J, Petrekanits M, Mészáros J, Farkas A: Anthropometric and physiological properties of football players. In Farkas Gy. (Ed.): Papers of the Scientific Session in Szeged (Hungary). SzegedUlm, 189-196 (1991) 
18. Mohácsi J, Mészáros J, Farkas A, Petrekanits M: Body composition and aerobic power of qualified Hungarian soccer players. Anthropológiai Közlemények, 38, 87-91 (1997)

19. Ng KN: Metabolic Calculations in Exercise and Fitness. Human Kinetics, Champaign, Illinois, 73-78 (1995)

20. Nieman DC (1995): Fitness and Sports Medicine. A Health-Related Approach. Bull Publishing Company, Palo Alto, California, pp. 599-616

21. Orvanova E, Hauspie R: Proportionality analysis of elite weight lifters. Humanbiologia Budapestinensis 18, 157-168 (1988)

22. Pollock ML, Foster C, Knapp D, Rod JL, Schmidt DH: Effect of age and training on aerobic capacity and body composition of master athletes. J. Appl. Physiol. 62, 725-731 (1987)

23. Ross WD, Ward R (1984): Proportionality of Olympic Athletes. In Carter JEL (Ed.): Physical Structure of Olympic Athletes, Part II. Kinanthropometry of Olympic Athletes. Karger, Basel, pp. 110-143

24. Shephard RJ, Åstrand, PO (Eds): Endurance in Sport. London, Blackwell Scientific.

25. Weiner JES, Lourie, JA (Eds) (1969): Human Biology. A Guide to Field Methods. IBP Handbook, No. 9. Oxford, Blackwell.

26. Wilmore JH: Body composition in sport and exercise: Directions for future research. Medicine and Science in Sports and Exercise 15, 21-31 (1983) 